\title{
Pulmonary Embolism: Epidemiological, Clinical, Therapeutic and Evolution Aspects in the Medicine Department of Hospital of Mali Bamako
}

\author{
Massama Konaté1,2*, Mariam Sako1,3, Boubacar Sonfo, ${ }^{1,4}$, Samba Sidibé1,3, Souleymane Mariko5, \\ Djeneba Sylla Sow ${ }^{1,2}$, Coumba Adjaratou Thiam,1,4, Djenebou Traoré6, Hamidou Oumar Ba1,7, \\ Asmaou Keita Maiga ${ }^{1,8}$, Ibrahima Sangare ${ }^{1,7}$, Mamadou Toure ${ }^{7}$, Souleymane Coulibaly1,3, \\ Nouhoum Diallo3, Bah Traoré2, Modibo Mariko², Nouhoum Ouologuem², Amadou Koné2, \\ Youssouf Camara1,4, Yacouba Lazare Diallo², Nanko Doumbia², Mahamadoun Coulibaly ${ }^{1,8}$, \\ Ichaka Menta ${ }^{1,7}$
}

\footnotetext{
${ }^{1}$ Faculty of Medicine and Dentistry (FMOS) of the University of Sciences, Technique and Technology of Bamako (USTTB), Bamako, Mali

${ }^{2}$ Medicine Department, Hospital of Mali, Bamako, Mali

${ }^{3}$ Cardiology department, CHU Point G, Bamako, Mali

${ }^{4}$ Cardiology Department, Hospital of Kati, Kati, Mali

${ }^{5}$ Medicine Department, Hospital of Tombouctou, Tombouctou, Mali

${ }^{6}$ Internal Medicine Department, CHU Point G, Bamako, Mali

${ }^{7}$ Cardiology Department, CHU Gabriel Toure, Bamako, Mali

${ }^{8}$ Cardiology Department, CHU Mère Enfant, Bamako, Mali

Email: *massamakonate@gmail.com
}

How to cite this paper: Konaté, M., Sako, M., Sonfo, B., Sidibé, S., Mariko, S., Sow, D.S., Thiam, C.A., Traoré, D., Ba, H.O., Maiga, A.K., Sangare, I., Toure, M., Coulibaly, S., Diallo, N., Traoré, B., Mariko, M., Ouologuem, N., Koné, A., Camara, Y., Diallo, Y.L., Doumbia, N., Coulibaly, M. and Menta, I. (2021) Pulmonary Embolism: Epidemiological, Clinical, Therapeutic and Evolution Aspects in the Medicine Department of Hospital of Mali Bamako. World Journal of Cardiovascular Diseases, 11, 242-248.

https://doi.org/10.4236/wjcd.2021.114024

Received: March 2, 2021

Accepted: April 17, 2021

Published: April 20, 2021

\begin{abstract}
Background: Pulmonary embolism (PE) is a severe form of venous thromboembolic disease. In Africa, prevalence of PE in hospitalized medical patients varies among studies. Objective: Aim of this work was to study the epidemiological, clinical, therapeutic and evolution aspects of PE in the medicine department of Mali's Hospital Bamako-Mali. Methodology: This was a retrospective cross-sectional study carried out from January 01, 2017 to December 31, 2020 in the medicine department of Mali's hospital Bamako, including all inpatients admitted for PE during the study period. Results: Of 1814 hospitalized patients, 54 patients had pulmonary embolism. Hospital frequency of pulmonary embolism was $2.97 \%$. Predominance was female and sex-ratio M/F was 0.38. Mean age in our series was $54.24 \pm 1.19$ years. Predisposing factors to pulmonary embolism were dominated by obesity $37 \%$, high blood pressure $35.2 \%$ and history of cardiovascular disease $20.4 \%$. Dominant signs were dyspnoea and chest pain in $83.3 \%$ and $70.4 \%$ of cases respectively.
\end{abstract}


Copyright ( 2021 by author(s) and Scientific Research Publishing Inc. This work is licensed under the Creative Commons Attribution-NonCommercial International License (CC BY-NC 4.0). http://creativecommons.org/licenses/by-nc/4.0/ (c) (i) () Open Access
Probability of pulmonary embolism was high in $40.7 \%$ according to Wells score. Patients with right heart failure were $22.2 \%$. EKG showed sinus tachycardia $70.4 \%$ and S1Q3 aspect 7.4\%. Heart right chambers were dilated at transthoracic echography $42.6 \%$. Obstruction was bilateral at chest angio CT for $51.9 \%$ and proximal for $42.6 \%$. Deep venous thrombosis was associated at EP in $16.6 \%$. Treatment was low weight molecular heparin followed by vitamin $\mathrm{K}$ antagonist or direct oral anticoagulant. One patient was successfully treated by thrombolysis. Hospital mortality was $16.7 \%$. Conclusion: PE is a serious disease probably underdiagnosed. It is responsible of important mortality.

\section{Keywords}

Pulmonary Embolism, Epidemiology, Mali’s Hospital

\section{Introduction}

Pulmonary embolism (PE) is a severe form of venous thromboembolic disease.

Annual incidence of this disease in the world is between 39 and 115 cases for 100,000 habitants [1]. It is thought to be responsible for 10,000 to 20,000 deaths per year worldwide.

In Africa, prevalence of $\mathrm{PE}$ in hospitalized medical patients varies among studies between $0.14 \%$ to $61.5 \%$, with a mortality rate between $13.7 \%$ and $69.5 \%$ [2] [3].

Mortality is higher in patients with undiagnosed and untreated PE [4]. Therefore, a better understanding of presentation of PE is necessary, so that diagnosis can be made early and treatment initiated. However, presentation of PE is highly variable and can pose diagnostic problems [5].

Diagnosis of deep venous thrombosis in a patient with suspected PE is sufficient to start anticoagulant therapy without further exploration [6].

Venous Doppler ultrasound of the lower limbs finds deep venous thrombosis in $30 \%$ to $50 \%$ of patients with PE [1].

In Mali, hospital studies have found a frequency of $1.6 \%$ at the CHU Point G [7] in 2006 and a frequency of $1.21 \%$ at the CHU Gabriel Touré [8] in 2018.

Few studies have focused on the epidemiology of pulmonary embolism, hence the motivation for this work, which aimed to identify the epidemiological, clinical, para-clinical, therapeutics and progressive characteristics of pulmonary embolism.

\section{Patients and Method}

This study was carried out in the medicine department of the Mali's hospital in Bamako, Mali.

This was a cross-sectional, descriptive and retrospective study which included all patients admitted with a diagnostic of pulmonary embolism by CT angiography between January 2017 and December 2020. Patients were identified using department's database. It involved files of all patients admitted with a diagnostic 
of pulmonary embolism by CT angiography. CT angiography was paraclinical exploration of diagnosis confirmation.

\subsection{Data Collection}

Medical files were retrieved from archives and following data were extracted: socio-demographic factors (age and sex), clinical presentation (chest pain, dyspnoea, haemoptysis, cough, syncope, pulse rate and blood pressure), comorbidities, risk factors of VTE, deep venous ultrasound, electrocardiogram, echocardiography, and CT angiography. Diagnosis of PE was defined by identification of a thrombus in pulmonary artery or any of its branches at CT angiography.

\subsection{Data Analysis}

Continuous variables were expressed as mean standard deviation. Dichotomous variables were expressed as counts and percentages.

Data entry and analysis were done with the software Microsoft Word 2010 and IBM SPSS 21.0 French version for Windows.

\subsection{Study Parameters}

Parameters of study were: socio-demographic data (age and sex), thromboembolic risk factors [1], diagnosis (frequency, clinical and paraclinical exams), medication used for the initial anticoagulant treatment and hospital outcome of inpatients.

\section{Results}

We collected 54 patients out of 1814 hospitalized patients, this mean hospital frequency of $2.97 \%$. Mean age of patients was $54.24 \pm 19.19$ years with extremes of 23 and 86 years. Patients aged 39 years and older accounted for $74 \%(n=40)$ (Table 1).

Female sex was predominant with sex ratio $\mathrm{M} / \mathrm{F}$ of 0.38 . Main symptoms were dyspnoea on exertion 83.3\% $(\mathrm{n}=45)$ and chest pain 70.4\% $(\mathrm{n}=38)($ Table 2$)$. Physical examination showed at admission right heart failure for $22.2 \%(\mathrm{n}=12)$ of patients, collapse for $18.5(n=10)$.

Risk factors for venous thromboembolism were dominated by obesity $37 \%$ ( $\mathrm{n}$ $=20)$, high blood pressure $35.2 \%(\mathrm{n}=19)$ and history of cardiovascular disease $20.4 \%(\mathrm{n}=11)$ (Table 3$)$.

Wells score was intermediate in 53.7\% $(\mathrm{n}=29)$ and high in $40.7 \%(\mathrm{n}=22)$.

EKG showed sinus tachycardia 70.4\% $(\mathrm{n}=38)$ and S1Q3 appearance $7.4 \%(\mathrm{n}$ $=4)$. Right chambers were dilated on cardiac ultrasound $42.6 \%(\mathrm{n}=23)$. PE was bilateral on CT angiography in $51.9 \%(\mathrm{n}=28)$ and proximal in $42.6 \%(\mathrm{n}=23)$.

Deep venous thrombosis was associated with PE in $16.7 \%(n=9)$.

The mortality risk score from European Society of Cardiology guidelines was low in $20.4 \%(\mathrm{n}=11)$, intermediate low in $50 \%(\mathrm{n}=27)$, intermediate high in $11.1 \%(n=6)$ and high in $18.5 \%(n=10)$. 
Table 1. Repartition of age range and gender.

\begin{tabular}{ccccc}
\hline Age range (years) gender & Female & Male & Frequency & Pourcentage \\
\hline$[23-39]$ & 12 & 2 & 14 & 25.9 \\
{$[39-55]$} & 12 & 2 & 14 & 25.9 \\
{$[55-71]$} & 9 & 3 & 12 & 22.2 \\
{$[71-87]$} & 6 & 8 & 14 & 25.9 \\
Total & 39 & 15 & 54 & 100 \\
\hline
\end{tabular}

Table 2. Repartition of symptoms.

\begin{tabular}{ccc}
\hline Symptoms & Frequency & Pourcentage \\
\hline Dyspnoea & 45 & 83.3 \\
Chest pain & 38 & 70.4 \\
Cough & 17 & 31.5 \\
Palpitation & 16 & 29.6 \\
Haemoptysis & 8 & 14.8 \\
Syncope & 5 & 9.3 \\
\hline
\end{tabular}

Table 3. Repartition of thromboembolism risk factors.

\begin{tabular}{ccc}
\hline Venous thromboembolism risk factors & Frequency & Pourcentage \\
\hline Obesity & 20 & 37 \\
High blood pression & 19 & 35.2 \\
History of cardiovascular disease & 11 & 20.4 \\
Diabetes mellitus & 8 & 14.8 \\
Cancer & 5 & 9.3 \\
Smoking & 4 & 7.4 \\
Oral contraception & 3 & 5.6 \\
Postpartum & 3 & 5.6 \\
Bed rest & 2 & 3.7 \\
Thrombophilia & 2 & 3.7 \\
Absence of risk factors & 5 & 9.3 \\
\hline
\end{tabular}

The first medication for anticoagulation was enoxaparin, a low molecular weight heparin at admission in $88.9 \%(n=48)$ of cases. The goal of international normalized ratio was between 2 and 3. Patients with renal failure at admission was $11.1 \%(n=6)$, they were treated with Calcium Heparinate. A relay by acenocoumarol and vitamin $\mathrm{K}$ antagonist was done in $88.9 \%(\mathrm{n}=48)$ of cases.

Rivaroxaban $15 \mathrm{mg}$ bid was introduced after initial anticoagulation by heparin in $11.1 \%(n=6)$ of patients. Ten patients had collapse during hospitalization.

One female patient who had collapse one day after admission underwent successful thrombolysis with Actilyse. Evolution during hospitalization was marked by death for 9 patients (16.7\%). Seven patients from who died had collapse. They 
did not benefit thrombolysis because of unavailability of medication.

\section{Discussion}

Limits of our study were his single-center character and retrospective method of collection of data.

Pulmonary embolism is an underdiagnosed disease due sometimes to the atypical clinical presentation. In Africa, hospital studies have found a PE frequency of $3.1 \%$ at Lomé, Togo [3]. In our series, hospital frequency was $2.9 \%$. Pulmonary embolism is a thromboembolic disease that increases in frequency with age. In Africa, some studies have found PE in people with a mean age around 50 years. At Lomé, average age was $52.7 \pm 14.4$ years with extremes of 27 and 81 years [3]. In Cameroon, average age of patients was 52 years [9].

In our study, mean age of our patients was $54.24 \pm 19.19$ years. Predominance was female with a sex ratio $\mathrm{M} / \mathrm{F}$ of 0.38 . The same result was observed in the CHU Gabriel Touré of Bamako with a sex ratio of 0.4 [8] and in the Pessinaba's one at Lomé with a sex ratio of 0.45 [3].

In our series, we noticed a female predominance for patients younger than 71 years old and it was male for patients older than 71 years. Women of childbearing age are more affected than men in the same age group. This difference could be explained by association of thromboembolic event with pregnancy and use of oral contraception. In contrast, the risk in older women is lower than that of men in the same age group [10]. Clinical signs of PE are nonspecific. In the majority of cases, PE is suspected in a patient with dyspnoea, chest pain, syncope or haemoptysis [1]. At Lomé, symptoms were dyspnoea (98.0\%), chest pain (78.4\%), cough (60.8\%), haemoptysis (31.4\%) and syncope (29.4\%) [3]. In Cameroon, it was dyspnoea (83.4\%), chest pain (78.6\%) and syncope (5.8\%) [9]. For our patients, main symptoms were exertion dyspnoea (83.3\%) and chest pain (70.4\%). In our series, $20.4 \%$ of patients had right heart failure. At Lomé, risk factors founded were hypertension and diabetes in $39.2 \%$ and $17.6 \%$ of cases, respectively [3]. In Cameroon, predominant risk factors were obesity (49.5\%), hypertension $(35.0 \%)$, recent long trip (24.3\%) and cancer (18.4\%) [9]. In our study, risk factors for venous thromboembolism were dominated by obesity (37\%), high blood pressure (35.2\%) and heart failure (22.2\%). Wells score was high in $40.7 \%$ of our patients. Wells score for PE was high in $49 \%$ of cases at Lomé [3]. EKG showed sinus tachycardia (70.4\%) and S1Q3 appearance (7.4\%). At Lomé, EKG noted sinus tachycardia (78.4\%), right heart hypertrophy (49.0\%) and an S1Q3T3 appearance (47.1\%) [3]. In Cameroon, sinus tachycardia was observed in $63.4 \%$ and S1Q3T3 appearance in 37.6\% [9]. Right heart cavities were dilated on cardiac ultrasound in $42.6 \%$ of our patients.

In Cameroon, right ventricular dilation was observed in $26 \%$ and systolic pulmonary pressure as high in 35\% [9].

In our series, PE was bilateral on CT angiography in $51.9 \%$ and proximal in 42.6\%. In Cameroon, PE was bilateral in $38.8 \%$ and proximal in $72.8 \%$ [9]. At 
Lomé in Togo, PE was bilateral in 57\%, right in 26\%, left in $17 \%$ [3].

Deep vein thrombosis (DVT) was associated with PE in $16.6 \%$. In Cameroon, DVT was associated in 24.3\% [9]. Menta [8] founded association PE and DVT in $38.09 \%$.

Majority of our patients were treated with low molecular weight heparin (LMWH). Patients with renal impairment (11.1\%) were treated with calcium heparinate. A relay by vitamin $\mathrm{K}$ antagonist (VKA) was done in $88.9 \%$. A direct oral anticoagulant (DOA), rivaroxaban was prescribed in $11.1 \%$ of patients. One patient underwent thrombolysis successfully with Actilyse. In Cameroon, initial anticoagulant treatment was LMWH followed by VKA in $89.3 \%$ and DOA (rivaroxaban) in $10.7 \%$ [9]. In our study, hospital mortality was $16.7 \%$ which is higher than rate founded by Pessinaba at Lomé with 13.7\% [3] and lower than those founded by Menta at Bamako [8] with 19.05\% and by Ngahane in Cameroon with $18.4 \%$ [9].

\section{Conclusion}

$\mathrm{PE}$ is a serious condition that is probably underdiagnosed. It is more common in women. Age of onset is younger in Africa compared to Europe. Clinic is dominated by dyspnoea and chest pain. With the epidemiological transition, predominant risk factors are obesity, hypertension and heart disease. Confirmatory diagnosis based on CT angiography is increasingly available in Africa. Direct oral anticoagulants take an increasingly important place in the therapeutic arsenal. Evolution of PE is marked by significant mortality.

\section{Conflicts of Interest}

The authors declare no conflicts of interest regarding the publication of this paper.

\section{References}

[1] Konstantinides, S.V., Meyer, G., Becattini, C., Bueno, H., Geersing, G.-J., Harjola, V.-P., et al. (2019) ESC Guidelines for the Diagnosis and Management of Acute Pulmonary Embolism Developed in Collaboration with the European Respiratory Society (ERS). European Heart Journal, 41, 543-603.

[2] Danwang, C., Temgoua, M.N., Agbor, V.N., Tankeu, A.T. and Noubiap, J.J. (2017) Epidemiology of Venous Thromboembolism in Africa: A Systematic Review and Meta-Analysis Protocol. BMJ Open, 7, e016223. https://bmjopen.bmj.com/content/7/10/e016223

[3] Pessinaba, S., Atti, Y.D.M., Baragou, S., Pio, M., Afassinou, Y., Kpélafia, M., Goeh-Akué, E. and Damorou, F. (2017) L'embolie pulmonaire au centre hospitalier universitaire campus de Lomé : Etude prospective à propos de 51 cas. The Pan African Medical Journal, 27, Article No. 129. https://doi.org/10.11604/pamj.2017.27.129.6855

[4] Calder, K.K., Herbert, M. and Henderson, S.O. (2005) The Mortality of Untreated Pulmonary Embolism in Emergency Department Patients. Annals of Emergency Medicine, 45, 302-310. https://doi.org/10.1016/j.annemergmed.2004.10.001 
[5] Bĕlohlávek, J., Dytrych, V. and Linhart, A. (2013) Pulmonary Embolism, Part I: Epidemiology, Risk Factors and Risk Stratification, Pathophysiology, Clinical Presentation, Diagnosis and Nonthrombotic Pulmonary Embolism. Experimental \& Clinical Cardiology, 18, 129-138.

[6] Le Gal, G., Righini, M., Sanchez, O., Roy, P.-M., Baba-Ahmed, M., Perrier, A., et al. (2006) A Positive Compression Ultrasonography of the Lower Limb Veins is Highly Predictive of Pulmonary Embolism on Computed Tomography in Suspected Patients. Journal of Thrombosis and Haemostasis, 95, 963-966.

https://doi.org/10.1160/TH06-03-0158

[7] Diall, I.B., Coulibaly, S., Minta, I., Ba, H.O., Diakite, M., Sidibe, N., Sangare, I., Diakite, S., Sanogo, K., Diallo, B.A. (2011) Etiologie, clinique et évolution de l'embolie pulmonaire à propos de 30 cas. Causes, signs and outcome of 30 patients with pulmonary embolus. Mali Medical, 26, $6 \mathrm{p}$.

[8] Menta, I., Coulibaly, S., Ba, H.O., Traore, D., Walbane, M., Camara, Y., et al. (2018) Pulmonary Embolism in Hospitalization in the Department of Cardiology of Gabriel Toure University Hospital. World Journal of Cardiovascular Diseases, 8, 18-23. https://doi.org/10.4236/wjcd.2018.81003

[9] Mbatchou Ngahane, B.H., Kamdem, F., Njonnou, S.R.S., Chebou, N., Dzudie, A., Ebongue, S.A., et al. (2019) Epidemiology, Clinical and Paraclinical Presentations of Pulmonary Embolism: A Cross-Sectional Study in a Sub-Saharan Africa Setting. Open Journal of Respiratory Diseases, 9, 89-99. https://doi.org/10.4236/ojrd.2019.93008

[10] Chalal, N. and Demmouche, A. (2013) Maladie thromboembolique veineuse dans la région de Sidi Bel Abbes, Algérie: fréquence et facteurs de risque. Pan African Medical Journal, 16, Article No. 45. https://doi.org/10.11604/pamj.2013.16.45.2620 